\title{
Sobre la Égloga del Santísimo Sacramento del jesuita Juan de Cigorondo
}

\author{
About jesuit Juan de \\ Cigorondo's Eclogue of Holy Sacrament
}

Alejandro Arteaga Martínez*

Resumen: El manuscrito 17286 de la Biblioteca Nacional de España y el 9/2573 de la Real Academia de la Historia conservan sendas versiones de una égloga sobre el Santísimo Sacramento del jesuita novohispano Juan de Cigorondo. Estudiamos la égloga en el contexto de la producción bucólica cigorondiana y la editamos críticamente tomando como texto base el conservado en la Nacional de España.

Palabras clave: bucolismo, égloga, jesuitas, poesía novohispana, poesía mexicana siglo XVI

Abstract: The manuscript 17286 of the National Library of Spain and the manuscript 9/2573 of the Royal Academy of the History conserve two versions of an eclogue on the Holy Sacrament of the New Spain Jesuit Juan de Cigorondo. The eclogue will be studied in the context of the bucolic Cigorondian production and it will be edited critically, taking as base-text the one preserved in the National of Spain.

Key Words: Bucolism, Eclogue, Jesuits, New Spain Poetry, Mexican Poetry of XVI Century

Recibido: 17 de octubre de 2016

Evaluado: 20 de noviembre de 2016

\footnotetext{
* Universidad Autónoma de la Ciudad de México.

E-mail: alejandro.arteaga@uacm.edu.mx
} 


\section{El autor y la obra}

El jesuita novohispano Juan de Cigorondo (Cádiz, 1560 - Nueva España/México, 1611) resulta ser uno de los autores literarios más prolíficos dada la extensión y calidad de su obra, que aborda los géneros dramático y poético, y está a caballo entre el siglo XVI y la primera década del XVII. Emigrado a Nueva España cuando probablemente tenía ocho años, ${ }^{1}$ la Compañía de Jesús admitió a Cigorondo en 1576, y este haría su profesión en $1592 .^{2}$ Entonces, el jesuita desempeñó cargos como profesor de gramática y retórica, rector de seminarios y colegios de la Compañía, así como socio de provinciales. $^{3}$

Hasta donde hemos investigado, la producción cigorondiana se conserva manuscrita en varias bibliotecas - la mayoría fuera de México-, e incluso algunas obras sin autoría se pueden relacionar con él, ya que en algunos casos se trata de copias de otras composiciones de autoría más segura. ${ }^{4}$ Nos interesan aquí dos composiciones poéticas: una égloga que se encuentra en los folios 306v-308r del manuscrito 17286 de la BNE titulada "Padre Ciguerondo. Égloga del Santísimo Sacramento"; 5 y otra que se encuentra en los folios 45v-48r del manuscrito 9/2573 de la RAH, anónima, titulada "Égloga del Santísimo sacramento entre Daminthas y Silvano, segador". 6 La segunda es, en realidad, una versión de la primera, con algunas variantes. La contextualización de esta pieza en el repertorio bucólico de Cigorondo, así como su edición crítica -que ofrecemos al final del presente estudio-, son los propósitos de este trabajo.

\section{La bucólica cigorondiana}

Para destacar la particularidad de la Égloga del Santísimo Sacramento, como nos referiremos en adelante a la composición que editamos, la enmarcaremos en el conjunto bucólico cigorondiano. ${ }^{7}$ Este grupo de composiciones es más bien breve dentro de la

\footnotetext{
${ }^{1}$ Arróniz, 1979: 176.

${ }^{2}$ Backer \& Backer, 1960: col. 44.

${ }^{3}$ Alonso Asenjo, 2006: 1vi; Zambrano \& Gutiérrez Casillas, 1970: 715; Zambrano \& Gutiérrez Casillas, 1975: 341.

${ }^{4}$ Enlistamos enseguida las fuentes manuscritas que conservan obra de Juan de Cigorondo:
}

a) El manuscrito 1631 de la Biblioteca Nacional de México (Yhmoff Cabrera, 1975: 197).

b) El manuscrito B2459 de The Hispanic Society of America (Rodríguez Moñino \& Brey Marino, 1965-1966: 421-424).

c) El manuscrito 17286 de la Biblioteca Nacional de España (BNE) (Paz \& Paz y Melia, 1934: 107108).

d) El manuscrito 18155 de la BNE titulado Églogas cancionero M.S.

e) El manuscrito 3669 (M. 33) de la BNE que contiene la Navegación del Alma de Eugenio de Salazar.

f) El manuscrito 9/2573 de la Real Academia de la Historia (RAH) (Menéndez Peláez, 2004: 486487).

g) El manuscrito 9/2581 de la RAH (Menéndez Peláez, 2004: 501).

${ }^{5}$ Biblioteca Nacional de España, MSS/17286. Cartapacio curioso de algunas comedias del padre Juan de Cigorondo de la Compañía del nombre de IHS, siglo XVII.

${ }^{6}$ Real Academia de la Historia, Ms. 9/2573 (Antiguo 392). Algunas poesías por varios autores, siglo XVI.

${ }^{7}$ La poesía bucólica o pastoril es un género de difícil definición: algunos investigadores consideran que la figura del pastor basta para que una obra forme parte de esta tradición bucólica o pastoril, mientras otros consideran necesario distinguir rasgos e intenciones en las obras, e incluso distinguir entre formas bucóli- 
obra de Cigorondo, pero extenso comparativamente, como veremos enseguida. Las composiciones bucólicas que hemos identificado del autor jesuita son las siguientes:

a) “Coloquio a la pastoril”, ms. 17286 BNE, ff. 95-124; composición de 1058 vv. ${ }^{8}$

b) "Égloga pastoril al nacimiento del niño Jesús", ms. 17286 BNE, ff. 169-210v; composición de $1509 \mathrm{vv} .^{9}$

c) "Églogas del engaño", ms. 17286 BNE, ff. 211-298v, 328-332v; composición de 3683 vv. $^{10}$

d) "Égloga del Santísimo Sacramento", ms. 17286 BNE, ff. 306v-308; composición de $110 \mathrm{vv}$.

e) "Égloga del Santísimo Sacramento entre Daminthas y Silvano, segador", ms. 9/2573 RAH, ff. 45v-48r; composición de 110 vv.

f) "Ecloga seu pastorum lusus, quorum subiectum Maria Magdalena est", ms. 18155 BNE, ff. 1-11r; composición de 1705 vv. ${ }^{11}$

La producción bucólica cigorondiana es breve si se le compara con el otro repertorio jesuita novohispano de poesía bucólica del siglo XVI. Este segundo conjunto bucólico se conserva en el manuscrito 1631 de la Nacional de México. Entre los folios 109r-144r del citado manuscrito, se reúnen diez composiciones del género; una égloga más aparece en el folio 148r; otra, muy posteriormente a este núcleo, pero carecemos de la referencia precisa del folio en nuestra copia del documento. ${ }^{12}$

Las doce composiciones bucólicas neolatinas superan en número a las seis de Cigorondo. Pero hay varias consideraciones qué hacer. Las composiciones neolatinas suman un total de 1352 versos; las de Cigorondo suman 8175 versos. Mientras que la composición más breve del repertorio del manuscrito 1631 es de 18 versos, la más breve de las églogas de Cigorondo tiene 110 versos. De igual modo, la composición más larga del manuscrito 1631 alcanza los 468 versos, pero la más larga de las églogas de Cigorondo tiene 3683 versos y es una obra inconclusa. Otro aspecto que debe señalarse es que el corpus del manuscrito 1631 está redactado totalmente en neolatín; en cambio, la producción bucólica cigorondiana lo está en español.

cas y materia pastoril. Será en los Idilios teocritanos donde se construyan cuadros pastoriles en los cuales se encontrarán formas poéticas y motivos característicos; por ejemplo, el canto amebeo, la búsqueda de la sombra para protegerse del calor, el tema erótico (Cristóbal, 2000: 16; Brioso Sánchez, 1986: 13-18). Las Bucólicas de Virgilio son un segundo hito en la formación del género bucólico. Si bien las Bucólicas tienden un puente hacia los Idilios (con algunas excepciones, como la bucólica IV), Virgilio consagra una combinación de motivos que dará estructura a esta tradición poética: "1) el paisaje silvestre; 2) el canto o música de los pastores; 3) el amor de los pastores; 4) la mitología (leyenda de Dafnis, edad de oro...); y 5) el atardecer" (Cristóbal, 2000: 31-32). El éxito medieval de las Bucólicas se acompañó de una lectura alegórica de la obra virgiliana que continuó hasta el Renacimiento (Gómez, 1991-1992: 115).

${ }^{8}$ Editada por Asenjo, 2012: 21-120.

${ }^{9}$ Editada por Arróniz (1979: 189-238) y, más recientemente, por Romero Salinas (2005: 87-130).

${ }^{10}$ Un acercamiento a esta obra se hizo en la comunicación de Arteaga Martínez \& Félix Pichardo (2015).

${ }^{11}$ Un análisis de esta obra se hizo en la comunicación de Arteaga Martínez (2016).

${ }^{12}$ La lista de composiciones neolatinas que forman el núcleo bucólico del manuscrito 1631 puede verse en Osorio Romero (1983). Algunas observaciones más recientes sobre el manuscrito referido las aporta Suárez (2015). La égloga del folio 148r la editó recientemente Ruiz Camacho (2016: 13-14). La égloga más alejada de este núcleo se titula "Ecloga in sanctum nonatum: Coridon, Lucia, Mopsus" (aproximadamente en los ff. 194v-195r; composición de $30 \mathrm{vv}$ ) y al parecer es inédita. 
Las églogas de Cigorondo aprovechan la materia bucólica y son formas dramáticas plenas, salvo la Égloga del Santísimo Sacramento. No es el caso de la mayoría de las composiciones del manuscrito 1631, muchas de las cuales son formas activas, pero no dramáticas; la excepción son los dos diálogos de Bernardino Llanos, ${ }^{13}$ que sí se representaron. A diferencia de las églogas del manuscrito 1631, cuya extensión oscila entre los 18 y los 468 versos, la extensión de las églogas de Cigorondo permite que el autor desarrolle estructuras más complejas sobre la materia pastoril, como examinaremos a continuación, y que lo acercan más a los autores peninsulares de églogas dramáticas.

\section{Descripción de las composiciones bucólicas de Cigorondo}

El Coloquio a lo pastoril es un buen ejemplo de cómo Cigorondo se relaciona con la tradición bucólica. A lo largo del Coloquio, el dramaturgo reproduce o parafrasea versos de las Bucólicas y de las Geórgicas de Virgilio, pero copia también a Ovidio. Asimismo aparecen versos y pasajes del Bucolicum Carmen de Petrarca y del Lusus pastoralis de Andrea Navagero. Lo que resulta más interesante, si cabe, es que Cigorondo cita o parafrasea versos y pasajes de los dos diálogos bucólico-dramáticos de Llanos, como demostró Alonso Asenjo, editor de la obra. ${ }^{14}$

La trama del Coloquio a lo pastoril tiene como eje la expectativa de los pastores ante la llegada anunciada y esperada de Alexis y Dafnis. El locus amoenus donde los pastores recogen flores, el canto amebeo y la competencia entre quienes cantan alabanzas por Alexis o por Dafnis, son algunos de los tópicos de la materia pastoril clásica presentes en esta obra. Junto a estos motivos, encontramos rasgos particulares de la dramaturgia del autor, como la exhibición sorpresiva de Apolo al abrir unas cortinas que lo han ocultado hasta el momento en que se anuncia su presencia; el recurso es semejante al uso de cortinas para ocultar a María Magdalena en la Comedia a la gloriosa Magdalena de Cigorondo. ${ }^{15}$ Asimismo, de naturaleza espectacular es el ofrecimiento de regalos desde la representación a los homenajeados; el recurso rompería la cuarta pared y evidenciaría la necesidad de una lectura alegórica del Coloquio, cuya intencionalidad laudatoria se encubrió tras las figuras pastoriles.

La Égloga pastoril al nacimiento del niño Jesús conserva algunos elementos esenciales de la materia bucólica en el primer plano de la obra: los pastores, el campo; pero prácticamente desaparecen los otros recursos de la tradición. La noche y el frío, contexto inicial de la obra, sustituyen al mediodía, al calor y a la sombra protectora que dicta la tradición. El canto amebeo aparece hacia el final. No se lamenta la ausencia de un sujeto apreciado sino hasta la quinta y última parte de la Égloga pastoril, cuando Placindo se retira a la soledad del campo y recuerda con nostalgia el pasado encuentro con el niño recién nacido.

No hay una relación explícita con un evento social que haga necesaria una lectura alegórica de la Égloga pastoril, pero sigue requiriéndose una lectura a lo divino: los pastores son el pueblo llano asombrado ante el nacimiento de un niño prodigioso, que el lector reconoce como el niño Jesús. La combinación de verso y prosa, de un paratexto como cierta carta que lee Placindo para explicar la naturaleza sobrehumana de lo ocu-

\footnotetext{
${ }^{13}$ Llanos, 1975; Llanos, 1982.

${ }^{14}$ Alonso Asenjo, 2012.

${ }^{15}$ Cigorondo, 2016.
} 
rrido, son rasgos de la dramaturgia cigorondiana: así, de nuevo en la Comedia a la gloriosa Magdalena, se lee un cartel que explica las condiciones del torneo y, en las Églogas del engaño, los pastores, convertidos en jueces de otro torneo, leen en voz alta los epigramas que presentan los concursantes convocados a la justa.

La Égloga pastoril al nacimiento del niño Jesús representa un punto importante en la producción jesuita que conocemos: se diría, con alguna vacilación, que estamos ante una pastorela jesuita, como las que se representaron en Zapotlán, Jalisco, en 1578, en Puebla en 1595 o en san Felipe de Sinaloa (Sinaloa de Leyva) en $1596 .{ }^{16}$ Nuestra vacilación surge porque en la Égloga pastoril no hay un conflicto entre el bien y el mal, entre los pastores y un demonio que pretenda impedirles reverenciar al niño Jesús recién nacido.

Las Églogas del engaño, la tercera composición de materia bucólica de Cigorondo, tienen una intención pedagógica. Estas églogas se organizan en triadas y cada grupo se nombra "bucólica", de manera parecida a lo que hace Petrarca en su Bucolicum carmen. Estas églogas demuestran la versatilidad que tiene el género pastoril en manos de Cigorondo. La precisa organización del texto corresponde a una división en actos y escenas. El elemento común a cada una de las partes es el ambiente campestre, con excepción de la bucólica segunda donde el espacio dramático es una escuela.

Los personajes de las Églogas del engaño son adultos, niños y alegorías. De los primeros, unos son pastores, otros agricultores. Los niños son hijos de estos campesinos $\mathrm{y}$, en general, se identifican unos a otros como pastores. Los adultos hacen iniciales y largas reflexiones sobre la crianza y educación de esos niños. Estos últimos, en su momento, se dedican al juego, aunque luego se verá a algunos como jóvenes adultos que asumen responsabilidades o se sumergen en los vicios. La intervención de los personajes alegóricos orienta la lectura hacia el descubrimiento de un sentido más profundo de las Églogas del engaño.

Las Églogas del engaño son una exposición del devenir de la humanidad y del camino de salvación por el que puede transitar el alma humana si lo desea. Así, entre la familia y la escuela se establece una comparación singular: el núcleo familiar ofrece una oportunidad única para cimentar valores en el niño; estos valores aumentan el potencial de la enseñanza escolar, porque si no hay tales cimientos, la escuela es inútil. Finalmente, se ofrece en esta extensa e inconclusa obra una sutil oposición entre el campo y la familia frente a la urbe y la escuela: mientras la familia protege al niño en el campo, en la escuela urbana el buen niño debe convivir con el malo. El riesgo de que el mal niño "contagie" con sus vicios y defectos de carácter al bueno es inminente si no hay un excelente maestro y un sólido respaldo familiar.

Varios motivos de la dramaturgia de Cigorondo reaparecen en las Églogas del engaño: la competencia entre los jóvenes pastores, pero sin el recurso del canto amebeo, la caza de pajarillos con redes (que había aparecido en la Égloga pastoril y en una de las obras de Llanos, también) o el sueño pesado que detiene a los jóvenes en sus obligaciones (motivo que aparece en la Égloga pastoril, en la Tragedia intitulada Ocio y en la Ecloga seu pastorum lusus).

Por último, la Ecloga seu pastorum lusus, quorum subiectum Maria Magdalena est, aunque anónima en el manuscrito 18155, ha sido atribuida con precisión a Cigorondo por rasgos estilísticos y temáticos comunes con obras de atribución más segura. La

${ }^{16}$ Lozano, 2007: 130; Híjar Ornelas, 2008: 48. 
obra se divide en cuatro secciones: un coro inicial que presenta a Magdalena lamentando su pasado; una sección argumental a cargo de uno de los pastores protagonistas, quien resume la trama; una primera sección en la que se presenta a un grupo de jóvenes pastores avanzando por el bosque que habitó Magdalena; una segunda parte donde los pastores abordan la cuestión de si fue la fe o el amor lo que le ganó el perdón a Magdalena.

Cigorondo explora en la Ecloga un asunto polémico: la cuestión de la salvación pasiva por la fe o de la salvación activa por las obras de amor o caridad. Sin que pretendamos ahondar en este tema, nos parece claro que se debate en la trama una problemática cercana a la crisis protestante del siglo XVI, pero el dramaturgo evita profundizar en abstracciones teológicas y, al utilizar el personaje de Magdalena, navega entre los diferentes argumentos de la polémica sin resultar pesado. La obra conserva agilidad dramática gracias a sus protagonistas, quienes bromean, juegan, discuten, pelean, organizan un torneo, se reconcilian y acuerdan que fueron las obras de amor las que salvaron a Magdalena. Este comportamiento lúdico de los personajes mantiene en constante movimiento el foco de atención del espectador, algo que ocurre en otras obras de Cigorondo.

La Ecloga pudo representarse o redactarse pensando en una puesta en escena segura. En el argumento y el cierre de la obra, se hace referencia a un "señor" cuya generosidad monetaria los jesuitas agradecen con esta obra. Por diferentes cuestiones contextuales -Cigorondo fue docente en el colegio de la ciudad de Puebla cuando la Compañía de Jesús recaudaba donaciones para la construcción del que sería luego el Colegio del Espíritu Santo-, creemos que la Ecloga pudo representarse entre el 22 de julio de 1585 y el 22 de julio de 1587. Pero la falta de evidencia documental sobre este asunto hace probable también que la pieza no se representara.

\section{Sobre la Égloga del Santísimo Sacramento}

La Égloga del Santísimo Sacramento es la más breve de las composiciones bucólicas de Cigorondo y la más relacionada con la materia y la forma pastoriles clásicas. Es también la que más se acerca a las églogas neolatinas del manuscrito 1631, tanto por su forma, extensión y tema. En 110 versos (seguimos el texto de la BNE), Cigorondo elabora una obrita que recuerda poderosamente la estructura teocritana: un narrador describe un espacio y un ambiente, y los personajes intervienen enseguida con parlamentos cuidadosamente alternados, aunque sin acotación de personaje. El preámbulo reúne los tópicos bucólicos referentes a la temporada estival, la reunión de los pastores a la sombra y la disposición de estos para competir con un canto amebeo, aunque sin un juez que tradicionalmente decide quién ha hecho la mejor alabanza en relación con el tema propuesto (vv. 1-16).

Amintas y Silvano, los pastores protagonistas de esta competición poética, elaboran sus cantos tratando de elogiar la mayor virtud del trigo o de la uva, que son las materias primas para la elaboración del pan y del vino empleados en el rito eucarístico. Conforme se desarrolla la competencia, Amintas elogia la forma de la uva y Silvano la de la espiga y el grano; pero ambos avanzan rápidamente hacia el elogio de las virtudes sobrenaturales que la uva y el trigo adquieren al representar, de alguna manera, a Cristo (vv. 91-94, 101-104). En este punto se hace evidente la innecesaria presencia del juez pastoril, porque no puede existir un ganador en esta competición: tanto la uva como el trigo, durante la transustanciación, se convierten en la sangre y el cuerpo de Cristo. 
La Égloga del Santísimo Sacramento requiere de una lectura alegórica a lo divino. Los elogios alternados a la vid y el trigo como productos de la tierra y del campo son, en otros términos, un reconocimiento de los múltiples dones que otorga libremente la divinidad al ser humano, tanto aquellos bienes materiales que preservan la vida corporal, como aquellos espirituales que alimentan al alma. Lo único que requiere el ser humano para acceder a tales dones, representados por la uva y el grano de trigo, es trabajar por ellos, como hace el campesino con su cosecha o el viñador con sus vides, para recibir la gracia en sus variadas manifestaciones.

Un rasgo particular de la Égloga del Santísimo Sacramento, que la acerca a las Églogas del engaño, es que no se incorporan los tradicionales pastores de bueyes al discurso bucólico, sino que aquí los personajes son dos tipos de campesinos: el agricultor Silvano, el viticultor Amintas. De modo que los tópicos de la materia pastoril que se aprovechan en esta composición son exclusivamente el espacio campestre y el canto amebeo como medio de dirimir qué "pastor" exalta con mayor mérito las propiedades de la vid o del trigo. La lectura alegórica de esta breve composición está guiada por el discurso de los campesinos cantores, sin que haya posibilidad de equivocar la intención subyacente.

A grandes rasgos, esta Égloga del Santísimo Sacramento y el resto de las composiciones bucólicas de Juan de Cigorondo aprovechan los tópicos de la materia pastoril: el espacio campestre, la competición reflejada en el canto amebeo y los juegos entre pastores; pero hay variaciones respecto de la tradición como el tiempo de la acción (la noche, en la Égloga pastoril al nacimiento del niño Jesús) o en la categoría de los personajes (pastores, agricultores, alegorías, niños, adultos). De modo que el poeta y dramaturgo jesuita novohispano parece haber orientado sus capacidades literarias hacia una modalidad bucólica que autores como Juan del Encina habían utilizado también para innovar dentro de la tradición pastoril clásica. Así que en Cigorondo podría percibirse la transición que experimentó la dramaturgia en lengua española en la transición entre el siglo XVI y el XVII.

\section{Criterios de edición}

Ofrecemos como apéndice de este trabajo la edición crítica de la Égloga al Santísimo Sacramento. Colocamos puntuación y acentuamos el texto siguiendo las normas actuales del español. Modernizamos el texto tomando en cuenta las reflexiones recogidas por Arellano y Rodríguez Garrido, y las recomendaciones de Arellano sobre la edición de la obra calderoniana: ${ }^{17}$ actualizamos cualquier variante gráfica que no tenga un valor fonológico exigido por el original, es decir, la grafía $\langle\mathrm{v}\rangle$ con valor vocálico se actualizará a $\langle\mathrm{u}\rangle$, las sibilantes $\langle\mathrm{z}, \mathrm{s}, \mathrm{ce}, \mathrm{ci}\rangle$ se actualizarán para seguir las normas de la Real Academia, etcétera.

Como indicamos, el texto de la Égloga del Santísimo Sacramento se conserva en los folios 306v-308r del manuscrito 17286 de la BNE, mientras que la versión titulada "Égloga del Santísimo Sacramento entre Daminthas y Silvano, segador" se conserva en los folios 45v-48r del manuscrito 9/2573 de la RAH. Elegimos BNE como texto base de nuestra edición porque consideramos que este manuscrito es una cuidada copia frente a las versiones de otras composiciones de Cigorondo que hemos podido cotejar.

${ }^{17}$ Arellano \& Rodríguez Garrido, 1999; Arellano, 2007. 
Las notas a pie nos sirven para explicar términos con ayuda de los diccionarios históricos de la Real Academia Española y, a veces, para parafrasear pasajes que consideramos dificultosos, cuando creemos haber entendido su sentido. Al finalizar la edición, ofrecemos un listado con las variantes entre los dos manuscritos. Descartamos aquellas discrepancias de carácter ortográfico, como explicamos antes, y conservamos aquellas que tratan de cambios sintácticos y léxicos.

Edición crítica de la Égloga del Santísimo Sacramento de Juan de Cigorondo

[306v]

\author{
Padre Ciguerondo \\ Égloga del Santísimo Sacramento
}

\author{
Cuando de ajenos $\operatorname{racimos}^{18}$ \\ se viste el olmo lozano \\ y de las blancas aristas ${ }^{19}$ \\ se desnuda el rojo grano, \\ pasaba al frescor y sombra \\ lo enojoso del verano ${ }^{20}$ \\ Amintas, el viñadero, \\ con el segador Silvano. \\ El uno, entre agro y dulce, \\ un gajuelo ${ }^{21}$ entre las manos; \\ el otro, de dos, enhila \\ diez espigas en la mano. \\ Ambos cantaban de apuesta ${ }^{22}$ \\ sin más jueces que el campo:
}

\footnotetext{
18 ajenos racimos: los frutos del olmo son racimos de sámaras, cada uno con una porción seminífera rodeada de un tejido llamada ala; cuando se secan los frutos, las sámaras se desprenden y hacen giros o planean al viento (Pontoppidan, 1991: 12). Los racimos del olmo le son ajenos porque no se quedan en él y se marchan con el viento. Además, como en el caso del grano que se indica en los versos siguientes, los racimos de sámaras anuncian el fin de un ciclo estacionario.

${ }^{19}$ blancas aristas: los filamentos de la cáscara que envuelve el grano del trigo.

${ }^{20}$ lo enojoso del verano: se refiere al calor molesto de esa temporada.

${ }^{21}$ gajuelo: cada uno de los grupos de uvas que integran el racimo.

${ }^{22}$ cantaban de apuesta: es tópico de la poesía bucólica que los pastores se enfrenten con cantos para dirimir quién tiene razón sobre un tema o quién hace el mejor elogio de una persona; suele haber un juez que elige al ganador. En esta égloga no aparece el juez. Por la extensión semejante de los parlamentos, podría pensarse que las intervenciones se organizan como un canto amebeo.
} 
sobre las uvas, Amintas;

sobre la espiga, Silvano.

Silvano $^{23}$ ¡Oh, rojo grano, espiga generosa,

vida del gusto y a la vista hermosa!

Amintas ¡Racimos francos, ${ }^{24}$ fértil parra hojosa: ${ }^{25}$

si bien pareces, eres más sabrosa!

Silvano

Si el recavo de las venas ${ }^{26}$

nos hace el oro preciado,

y añade estima a las perlas

de la conchuela el resguardo,

[307r] veros de capa y capote

salir tan arrebozado,

con parapeto de aristas, ${ }^{27}$

no debe de ser en vano.

¡Oh, rojo grano, espiga generosa,

vida del gusto y a la vista hermosa!

Amintas

¿Qué proporción de techumbre ${ }^{28}$

trazará el árabe ufano

en lazos, talla y pintura

sobre columnas de mármol,

que llegase al artificio

del gentil techo galano

que, entre pámpano y sarmiento, ${ }^{29}$

\footnotetext{
${ }^{23}$ Silvano: ninguna de las dos versiones de esta composición utiliza acotaciones de personaje; en esta edición, por lo tanto, todas las atribuciones de parlamento son nuestras.

${ }^{24}$ racimos francos: los racimos ofrecen con liberalidad o abundancia una porción de uvas.

${ }^{25}$ parra hojosa: la vid que tiene muchas hojas.

${ }^{26}$ recavo de las venas: recavar o excavar siguiendo el filón de mineral es un trabajo ingrato que tiene como premio descubrir el metal precioso; lo poco vistoso de la tarea se parece a la almeja, que esconde la perla como un tesoro.

${ }^{27}$ parapeto de aristas: el grano de trigo está cubierto de la cascarilla dura y áspera, que se prolonga en un filamento puntiagudo y reseco (la arista), que pincha como una púa protectora. Detrás de la apariencia poco amigable al tacto, debe esconderse algo valioso, como el oro en el filón o la perla en la almeja.

${ }^{28}$ proporción de techumbre: la correspondencia y disposición adecuada entre las partes del techo imaginario que trenzan las vides de modo natural, excede a las filigranas que podrían hacer los constructores árabes.

${ }^{29}$ pámpano y sarmiento: se trata de las ramas de la vid donde cuelgan las uvas: el pámpano es la verde, tierna y delgada, es decir, que apenas brota, mientras que el sarmiento es el vástago ya maduro y listo para sostener los racimos de uvas que saldrán de él.
} 
tejéis sobre el tronco y ramos?

¡Racimos francos, fértil parra hojosa:

si bien pareces, eres más sabrosa!

Silvano El escarlatín y el ámbar, ${ }^{30}$

que son de la rosa el baño,

dieron que ver a los ojos

y el gusto quedose en vano. ${ }^{31}$

Pero vos, con ese lustre

que el sol os dio con sus rayos

tan parecido al del oro,

sois en el teatro humano. ${ }^{32}$

¡Oh, rojo grano, espiga generosa,

vida del gusto y a la vista hermosa!

Amintas El bálsamo a gotas hecho

y el sudor que estila el nardo ${ }^{33}$

sueldan el rigor del filo ${ }^{34}$

y en olor son el regalo.

[307v] Mas ese licor que encierran

esos brincos de alabastro, ${ }^{35}$

cuanto es de alivio el olerlo

tanto es más vida el gustarlo. ${ }^{36}$

\footnotetext{
${ }^{30}$ El escarlatín y el ámbar: se trata del color y el aroma de la rosa, pues el escarlatín es un tono de escarlata más tenue, mientras que el ámbar es una goma o betún aromático y de color amarillo.

${ }^{31}$ quedose en vano: la rosa agrada a la vista, pero su belleza es efímera y, por esta causa, es un gusto vano, inútil.

${ }^{32}$ sois en el teatro humano: es probable que esto sea una referencia a la presencia de Cristo en el pan consagrado, que representa su cuerpo. El "teatro" deberá entenderse, entonces, como "teatro del mundo".

33 el nardo: de esta planta aromática, de hojas lanceoladas, se hacen mezclas perfumadas; María Magdalena usaría de ellas para ungir los pies de Cristo.

34 sueldan el rigor del filo: no entiendo el sentido de esta línea. Quizá, en relación con la referencia a Magdalena que puede invocarse por el uso del perfume de nardo (y que parece extenderse al resto del parlamento), cabría recuperar la expresión "darse un filo", por un lado, que Autoridades define como juntarse varias personas para murmurar de alguien más (s. v. filo); y, por otro, la segunda acepción de soldar, de la cual dice el citado diccionario que "Metafóricamente vale componer, enmendar y disculpar algún desacierto con algunas acciones o palabras, para que quede satisfecho quien las notó". En Lucas 7: 36-50, se cuenta cómo entró Magdalena a la casa de Simón y, llorando, lavó y perfumó los pies de Cristo, ante la incomodidad del dueño de la casa, cuyos pensamientos críticos acalló Jesús al contarle una parábola. De modo que las murmuraciones contra Magdalena ("rigor del filo") fueron soldadas o disculpadas con la defensa oral que Jesús hizo de la mujer.

${ }^{35}$ brincos de alabastro: se trata de un joyel pequeño que colgaba de los tocados y parecía brincar con el movimiento de la persona. Aquí parecen ser piezas huecas que contienen perfume de nardo.
} 
¡Racimos francos, fértil parra hojosa:

si bien pareces, eres más sabrosa!

Silvano Por ver lo que os va en los tiempos, ${ }^{37}$

lleva el labrador a un paso

la vista alta en el cielo, ${ }^{38}$

la mano baja al arado.

$\mathrm{Y}$ en veros, con mayor colmo,

de muerto, resucitado, ${ }^{39}$

sois esperanza a los vivos

y ofrenda a los sepultados. ${ }^{40}$

¡Oh, rojo grano, espiga generosa,

vida del gusto y a la vista hermosa!

Amintas En el que os gusta al descuido,

dais por portazgo ${ }^{41}$ en los labios

dos amapolas al rostro

y a los ojos, sendos rayos.

Y como es tan señoril

vuestro humor, al primer paso

se le sube a la cabeza

\footnotetext{
${ }^{36}$ es más vida el gustarlo: de nuevo en relación con el pasaje de Lucas 7: 36-50, hay que recordar que la unción con perfume que hizo Magdalena debió llenar la casa de Simón de un agradable aroma, pero todavía hubo un beneficio mayor de este perfume para la vida de la mujer, pues Jesús perdonó los pecados de Magdalena y la despidió con su bendición.

${ }^{37}$ los tiempos: sinónimo de las estaciones anuales.

${ }^{38}$ la vista alta en el cielo: que este pastor-labrador mire el cielo para apercibirse del clima y prever el futuro de su trabajo en el campo (como ocurre con las requintas o cabañuelas), es un motivo que aparece en las Églogas del engaño de Cigorondo. Dice ahí el pastor Tigrenio: "Eso va así y, a veces, reclinado / sobre la hierba en la enojosa siesta / o a las tardes, al paso del ganado, / traigo la vista levantada, enhiesta, / mirando d'esos cielos la grandeza / tan variable, tan en orden puesta. / Considero del sol la ligereza / en su largo camino y la mudanza / en la luna, en la tierra la firmeza" (vv. 1174-1182).

${ }^{39}$ de muerto, resucitado: se refiere al grano que, en cuanto semilla, parece inerte; pero sembrado y cuidado, germina y revive. Esto podría entenderse como una alegoría de la resurrección de Cristo.

${ }^{40}$ los sepultados: los vv. 63-64 hacen alusión a los pasajes de Colosenses 2: 12 y Romanos 6: 4, 8, en los cuales se afirma que el cristiano fue sepultado con Cristo en el bautismo y resucitado con él a una vida nueva. El trigo usado en el pan de la Eucaristía representa efectivamente la resurrección de Cristo mediante la transustanciación. El pan eucarístico hecho con el grano de trigo demuestra la esperanza de la resurrección futura a los creyentes vivos, pero como ofrecimiento en la comunión, es la ofrenda a los sepultados en el bautismo.

${ }^{41}$ portazgo: el impuesto que se paga por pasar por algún sitio. Los vv. 67-69 exponen cómo el vino ingerido de manera casual tiene efectos embriagantes (el portazgo por beberlo) que se manifiestan en el enrojecimiento del rostro y el brillo en la mirada. En contraste, la segunda parte de esta estrofa afirma que idéntico vino, pero consagrado, tiene efectos milagros.
} 
y en ella hacéis milagros. ${ }^{42}$

¡Racimos francos, fértil parra hojosa:

si bien pareces, eres más sabrosa!

Silvano

[308r]

¿Que falte el polvo en la Arabia

y no nos hile el gusano!

Poco alterarán el tiempo

la voz de barato o caro.

Pero en vos como acudierdes

en los sulcos, ${ }^{43}$ se da el trato:

si a lo corto es carestía,

si a lo largo ese es buen año. ${ }^{44}$

$¡ O h$, rojo grano, espiga generosa,

vida del gusto y a la vista hermosa!

Amintas

Licor, lo que os engrandece

es llegar Cristo a tomaros

por sombra de sus misterios,

por prenda de sus regalos.

Si no, dígalo este día

donde llega a punto el cambio,

que encierra él en su pecho

todo lo que es Dios de un trago. ${ }^{45}$

¡Racimos francos, fértil parra hojosa:

si bien pareces, eres más sabrosa!

Silvano Espiga, cuando sois menos,

llegáis sin ser a ser tanto,

que en abarcar sois un cielo

y en lo que encerráis, sagrario.

\footnotetext{
${ }^{42}$ hacéis milagros: no entiendo el sentido de los vv. 71-73, pero podría tratarse de una referencia al vino consagrado que representa la sangre de Cristo, idea que complementaría la del pan en la estrofa anterior y en las últimas dos.

${ }^{43}$ acudierdes / en los sulcos: 'acudir' es, en este caso, ser abundante; 'sulcos' es otra forma de surcos.

${ }^{44}$ ese es buen año: en la estrofa se hace un contraste, pues aunque ocurriera lo impensable (que no hubiera arena en Arabia) o lo calamitoso (que el gusano de seda no hilara su capullo), lo único importante para el pastor-campesino es su cosecha, con la que puede evaluar el resultado de su esfuerzo.

${ }^{45}$ lo que es Dios de un trago: la estrofa se refiere a la transformación del vino en la sangre de Cristo durante la consagración eucarística.
} 
Y ansí, sin quedar de vos

más que ese aparente blanco,

venís a sernos, de veras,

por un modo soberano. ${ }^{46}$

¡Oh, rojo grano, espiga generosa,

vida del gusto y a la vista hermosa!

110

\section{Lista de variantes}

Siguiendo a Arellano (2007), señalamos el verso del texto base donde ocurre la variación y, en cursivas, copiamos el segmento modernizado del manuscrito 17286 de la BNE; mientras que tras un corchete de cierre y en redondas, queda la versión paleográfica del manuscrito 9/2573 de la RAH.

v. 1a Padre [...] Sacramento ] Egloga del Santissimo sacramento entre daminthas y silvano segador. dizen alternatins

v. 5 al frescor y sombra ] el frescor y sombras

v. 7 Amintas ] Damintas

v. 10 entre las manos ] el mas temprano

v. $11 \mathrm{el}] \mathrm{y}$ el

v. 18 la vista ] la vida

v. 20 sabrosa ] hermosa

v. 52 el sudor ] el liquor

v. 76 vuestro ] nuestro

v. 77 se le ] se nos

v. 82 Y no nos] o no nos

v. 83 Poco alterarán ] poco alterara en

v. 85 acudierdes ] acudieredes

v. 86 se da ] se yra

v. 93 es llegar ] es venir

v. 96 donde llega ] en q llega

v. 102 Y ansí] y al fin

\footnotetext{
${ }^{46}$ un modo soberano: para completar la imagen eucarística, en esta última estrofa se hace referencia al trigo convertido en harina ("sin quedar de vos / más que ese aparente blanco"), cuya insignificancia no es tal al elaborarse el pan que se convierte en el cuerpo de Cristo en la transustanciación, pero que, además, se conserva presente y se exhibe en el sagrario.
} 


\section{Referencias}

Alonso Asenjo, J. (2006). "Tragedia intitulada Oçio" de Juan de Cigorondo y teatro de colegio novohispano del siglo XVI. Ciudad de México: El Colegio de México.

(2012). Teatro colegial de México a Chile. València: Publicacions de la Universitat de València.

Arellano, I. \& Rodríguez Garrido, J. (1999). Edición y anotación de textos coloniales hispanoamericanos. Madrid - Frankfurt am Main: Iberoamericana - Vervuert.

Arellano, I. (2007). Editar a Calderón: hacia una edición crítica de las comedias completas. Madrid - Frankfurt am Main: Universidad de Navarra - Iberoamericana Vervuert.

Arróniz, O. (1979). Teatro de evangelización en Nueva España. Ciudad de México: Universidad Nacional Autónoma de México.

Arteaga Martínez, A. (2016). Sobre la "Égloga o juego de pastores, cuyo tema es María Magdalena". Comunicación presentada en el XXIX Encuentro Nacional de Investigadores del Pensamiento Novohispano "Roberto Heredia Correa". Aguascalientes, México.

Arteaga Martínez, A. \& Félix Pichardo, A. L. (2015). Acerca de las Églogas del engaño del jesuita Juan de Cigorondo. Comunicación presentada en el 1er Coloquio Internacional de Cultura Literaria Virreinal. Zacatecas, México.

Backer, A. de \& Backer, A. de (1960). Bibliothèque de la Compagnie de Jesús. Louvain: Editions de la Bibliothéque S. J., vol. 9.

Brioso Sánchez, M. (1986). Introducción. En Bucólicos griegos (9-46). Madrid: Akal.

Cigorondo, J. (2016). Comedia a la gloriosa Magdalena. Ed. A. Arteaga Martínez. Ciudad de México: Bonilla Artigas Editores - Universidad Autónoma de la Ciudad de México.

Cristóbal, V. (2000). Introducción. En Virgilio, Bucólicas (7-67). Madrid: Cátedra.

Dios habla hoy. La Biblia con deuterocanónicos. Ciudad de México: Sociedades Bíblicas Unidas, 1987.

Gómez, J. (1991-1992). Sobre la teoría de la bucólica en el Siglo de Oro: hacia las églogas de Garcilaso. Dicenda. Cuadernos de Filología Hispánica, 10, 111-125.

Híjar Ornelas, T. de (2008). Las pastorelas de Jalisco. Antecedentes, desarrollo y pervivencia de los coloquios de pastores en el Occidente de México. Jalisco: Secretaría de Cultura - Gobierno del Estado de Jalisco.

Llanos, B. de (1982). Diálogo en la visita de los inquisidores, representado en el Colegio de San Ildefonso (siglo XVI), y otros poemas inéditos. Ed. J. Quiñones Melgoza. Ciudad de México: Universidad Nacional Autónoma de México.

(1975). Égloga por la llegada del padre Antonio de Mendoza representada en el Colegio de San Ildefonso (siglo XVI). Ed. J. Quiñones Melgoza. Ciudad de México: Universidad Nacional Autónoma de México.

Lozano, T. (2007). Cantemos al alba. Origins of Songs, Sounds, and Liturgical Drama of Hispanic New Mexico. Alburquerque: University of New Mexico Press. 
Menéndez Peláez, J. (2004). Los jesuitas y el teatro en el Siglo de Oro: repertorio de obras conservadas y de referencia. Archivum. Revista de la Facultad de Filología, 54-55, 421-563.

Osorio Romero, I. (1983). Doce poemas neolatinos de fines del siglo XVI novohispano. Nova Tellvs, 1, 171-203.

Paz, J. \& Paz y Melia, A. (1934). Catálogo de las piezas de teatro que se conservan en el Departamento de Manuscritos de la Biblioteca Nacional. Madrid: Blass Tipográfica, vol. 1.

Pontoppidan, A. (1999). El olmo. Trad. S. Herreros. Madrid: Akal.

Rodríguez Moñino, A. \& Brey Mariño, Ma. (1965-1966). Catálogo de los manuscritos poéticos castellanos existentes en la Biblioteca de The Hispanic Society of America (siglos XV, XVI y XVII). New York: The Hispanic Society of America, vol. 2.

Romero Salinas, J. (2005). La pastorela y el diablo en México. Ciudad de México: Porrúa.

Ruiz Camacho, O. (2016). Seis églogas neolatinas novohispanas y un epigrama del siglo XVI (tesis de maestría). Universidad Nacional Autónoma de México, Ciudad de México, México.

Suárez, M. A. (2015). La Ecloga de aduentu proregis Ludouici de Velasco del Ms. 1631 (BNM): género de circunstancia y modelo virgiliano. IHS. Antiguos jesuitas en Iberoamérica, 3(1), 86-95.

Yhmoff Cabrera, J. (1975). Catálogo de obras manuscritas en latín de la Biblioteca Nacional de México. Ciudad de México: Universidad Nacional Autónoma de México.

Zambrano, F. \& Gutiérrez Casillas, J. (1970). Diccionario bio-bibliográfico de la Compañía de Jesús en México. Ciudad de México: Jus - Tradición, vol. 10.

(1975). Diccionario bio-bibliográfico de la Compañia de Jesús en México. Ciudad de México: Jus - Tradición, vol. 14. 